\title{
Turbine Load Oscillation Fault Caused by Its HP-Valve Problem
}

\author{
Xingshuo $\mathrm{Li}^{1, \mathrm{a}}$, Zhuo $\mathrm{Xu}^{2, \mathrm{~b}}$, Jie $\mathrm{Wan}^{1, \mathrm{c}^{*}}$, Jianguo Sun ${ }^{3, \mathrm{~d}}$, Jing $\mathrm{Su}^{3, \mathrm{e}}$, \\ Fei Jiang ${ }^{3, \mathrm{f}}$, Hong Liü ${ }^{4, \mathrm{~g}}$, Tiemiao Liu ${ }^{5, \mathrm{~h}}$, Jishan Liu ${ }^{3, \mathrm{i}}$, Jun Zhao ${ }^{3, \mathrm{j}}$, Peigang Yan ${ }^{1, \mathrm{k}}$ \\ ${ }^{1}$ School of Energy Science and Engineering, Harbin Institute of Technology, Harbin, Heilongjiang, \\ 150001, China \\ ${ }^{2}$ Jinqiao Thermal Power Plant of Huaneng North Unites Power Co. Ltd, Huhehaote, Inner \\ Mongolian, 014300, China \\ ${ }^{3}$ Dalate Power Plant of North Unites Power Co. Ltd, Dalate, Inner Mongolian, 014300, China \\ ${ }^{4}$ Heilongjiang Institute of Architectural Technology, Harbin, Heilongjiang, 150025, China \\ ${ }^{5}$ Weijiamao Coal Power Co. Ltd of Huaneng North Unites the Electric Power Co. Ltd, Zhunger, \\ Inner Mongolian, 010308, China \\ a 459438841@qq.com, b13848518824@163.com, cwhhitwanjie@126.com, \\ 'sunjiangu0950118@sina.com, ${ }^{\mathrm{e}}$ suwls@126.com,'nmjf001@sina.com, ${ }^{9} 29205278 @ q q . c o m$, \\ hliutiemiao123@163.com, ${ }^{\mathrm{i}}$ 104167602@qq.com, ${ }^{\mathrm{j}}$ 13847234144@163.com, ${ }^{\mathrm{k}}$ peigang_y@163.com
}

Keywords: Turbine, Load regulation, Load oscillation, Fault, HP-valve problem.

Abstract. Currently, the increasing scale wind power paralleling in grid leads the range and frequent degree of thermal power unit regulating system action become larger than ever. So both the units' regulation performance requirements become higher and units' regulation system equipment performance faces more severe test. It's found that not only HP-valve's poor flow characteristics of software failure, but its loose connection parts of hardware failure can also cause unit load oscillation on based of studying two actual unit cases. Then, a method for fault identification with online monitoring are shown. Finally, the common optimization for two kind HP-valves' fault is carried out with great engineering application value to guarantee units operation with safety and efficient.

\section{Introduction}

Currently, strong random uncertainty of the increasingly large-scale new energy connecting to grid has made power system face more serious consumption problem than ever, and more diverse energy supplies with wide range of complementary characteristics have been needed to meet constant balance of power system [1-3]. However, the dominant role of thermal power leads to the power structural contradictions in China, which caused the lack of power source to stabilize the uncertainty of new energy power. And a great number of large thermal power units began to participate in grid regulation with the larger range and frequent degree of unit regulating system action. Therefore, the occurrence rate and complex degree of its fault is also more than ever [4]. And lots of related work are carried out to enhance the thermal power units' economy and safety under wide range variable load operation [5,6]. The steam turbine regulates power with HP-valve to control steam flow [5]. And the sequence valve is a more economic operation pattern than single valve model. In addition the sliding pressure operation that recognized as one of the most effective method to improve turbines part load economy [6-9]. However, the designation of sequence valve inappropriate rule that affect the safe and stable operation of the unit is a very complex job [9-12]. And load oscillation is one of serious problem that can affect the ability of unit frequency regulation and peak regulation even can caused grid load oscillation. So many researchers have been concerned with correlation study. And it's found that HP-valve's poor flow characteristics, called software failure, can cause the load oscillation. However there isn't enough research on load oscillation caused by hardware failure. In this paper, we found that the HP-valve's hardware failure can also cause unit load oscillation. And a fault identification method are shown with great engineering application value. 


\section{Load Oscillation Caused by Software Fault of HP-valve}

There are many reasons that can caused load oscillation under the sequence valve operation mode. And the most common reason is the software failure that the flow characteristic curve design of high regulation valves does not match the actual flow characteristics. In Fig.1, a case of load oscillation problem caused by the software failure in a supercritical 350MW unit is presented.

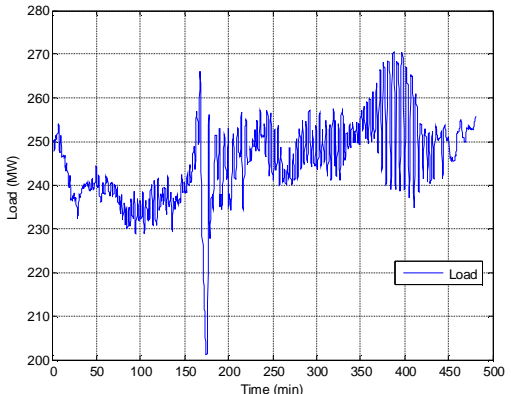

(a)Load variation trend

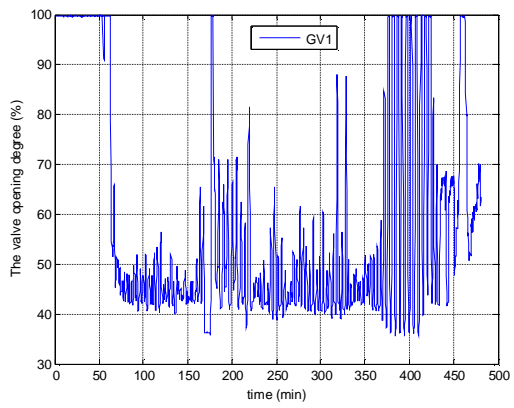

(e) GV1 variation trend

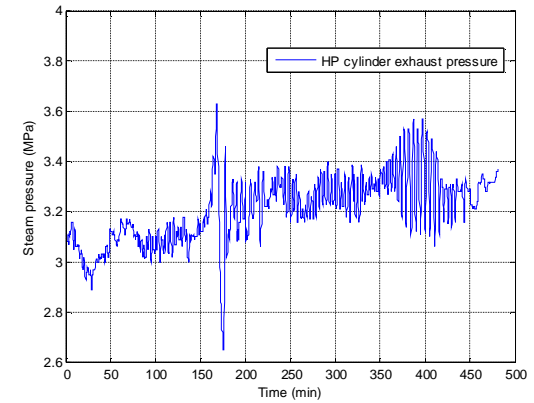

(h) HP cylinder exhaust pressure

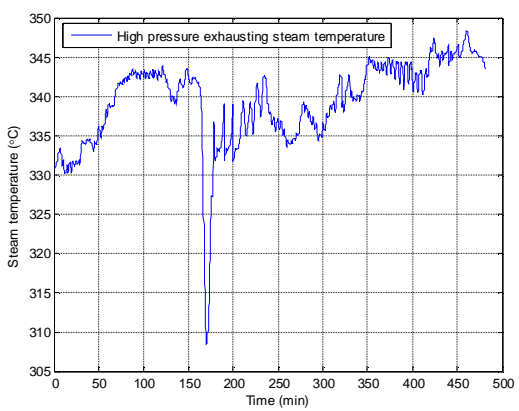

(k) HP exhausting steam temperature

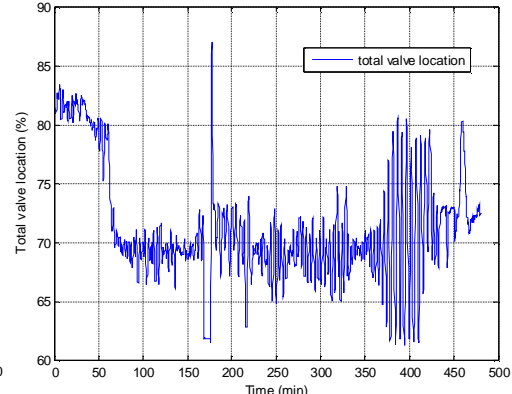

(b) Total valve location variation trend

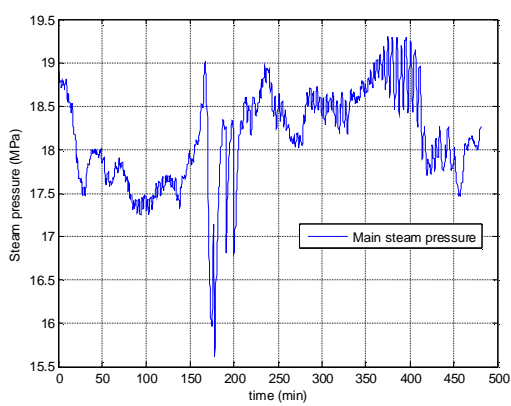

(g)

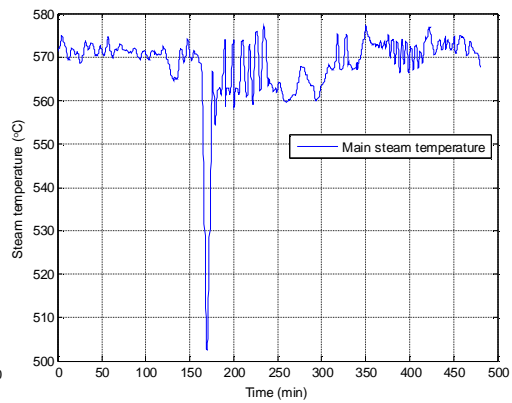

(i) Main steam temperature

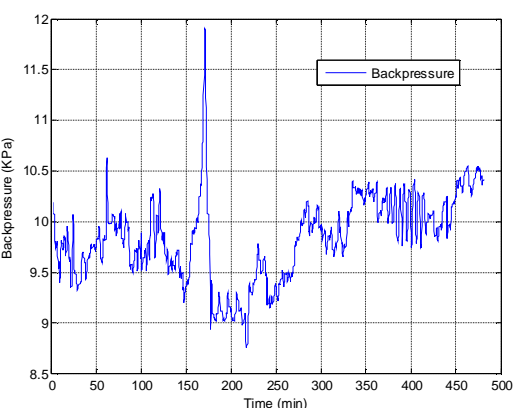

(1) Backpressure variation trend

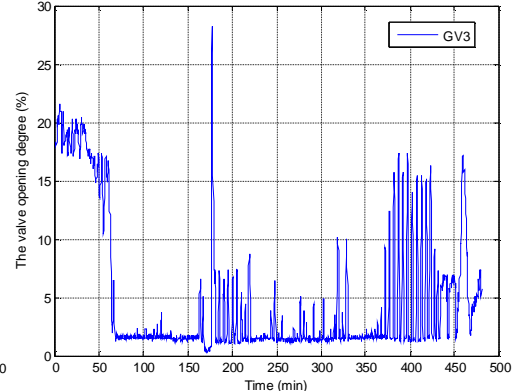

(c) GV3 variation trend

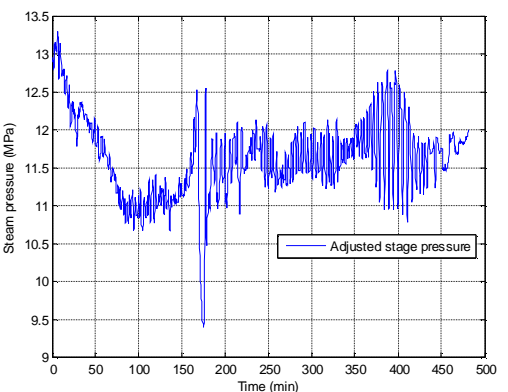

Fig.1 Load oscillation problem caused by the software failure

Furthermore, Fig.1 can also reveal the degree of this kind fault doing harm to the unit. When this kind fault occurring, many of the parameters will happen following swing matter, including the total valve location, the valve opening degree, Main steam pressure, adjusted stage pressure, HP cylinder exhaust pressure, the main steam temperature, regulating stage steam temperature, HP exhausting steam temperature, even the backpressure variation trend and EH oil pressure. Therefore, this kind load oscillation will influence the units' regulation performance enormously, especially to turbine's automatic generation controlling and primary frequency modulation. 


\section{Load Oscillation Caused by HP-Valves' Hardware Malfunction}

In fact, high pressure valves' hardware failure can also cause unit load oscillation, for example the valve parts' loose connection. As shown in Fig.2, a case of load sloshing phenomenon caused by hardware failure in subcritical 330MW unit is presented. It's found the load sloshing took place at three load conditions including $300 \mathrm{MW}, 280 \mathrm{MW}$ and $240 \mathrm{MW}$, which can greatly affect the unit's regulation performance. This further shows that the fault degree is very serious, which have a common fault feature. For GV3, the emergence position of valve sloshing is between $30 \%$ and $35 \%$. For GV4, the emergence position of valve sloshing is between $7 \%$ and $12 \%$. Therefore, this kind load oscillation also influences the units' regulation performance enormously.
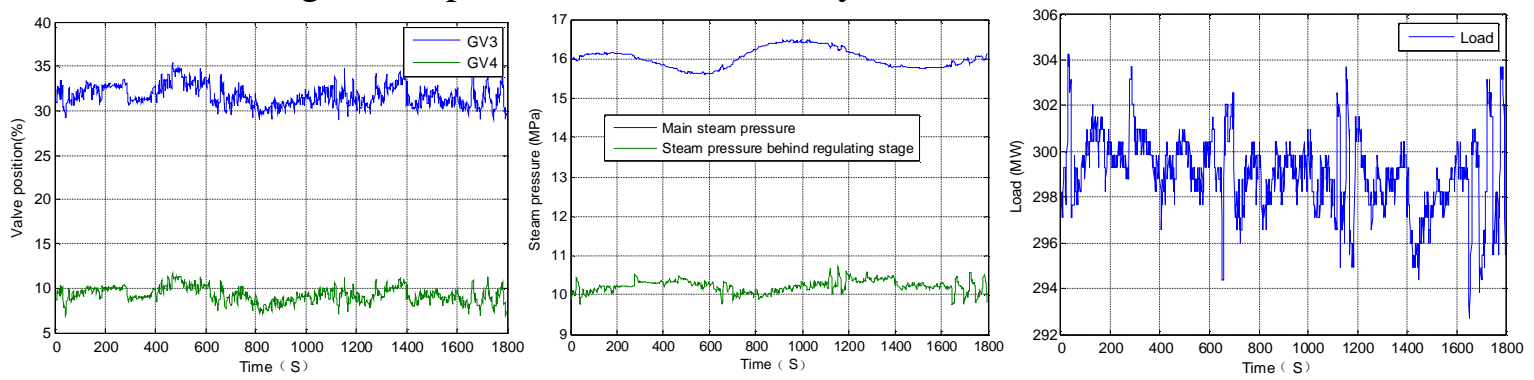

(a) Valve sloshing under 300MW load condition
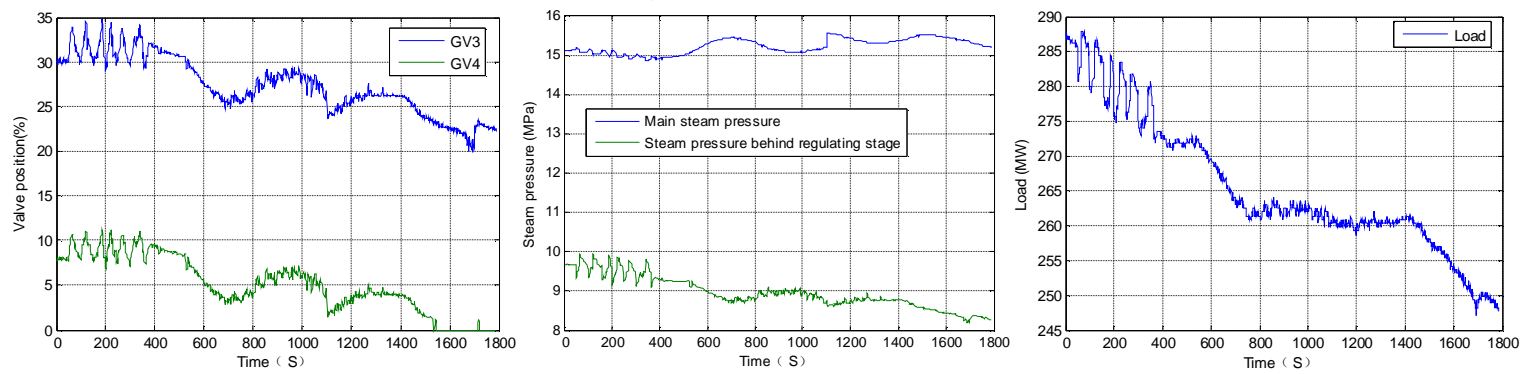

(b) Valve sloshing under 280MW load condition
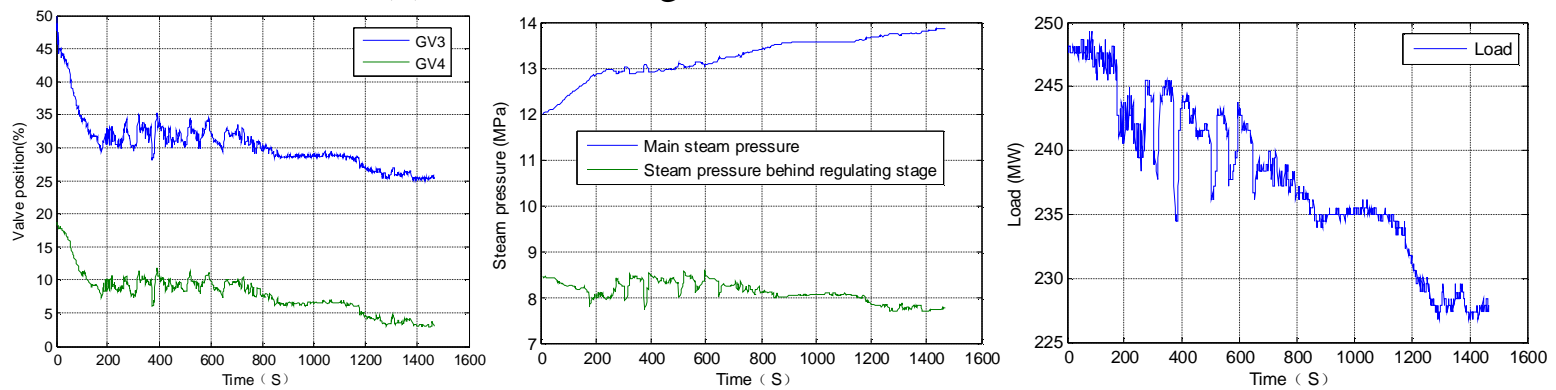

(c) Valve sloshing under 240MW load condition

Fig.2 The load sloshing phenomenon caused by hardware failure

\section{The Fault identification method}

Because of the large danger of two kinds of faults, practical fault recognition is very important. So a fast fault detection method based on daily operation data is proposed. And this is also a method to defense fault initiatively, which is by calculating the Linearity of characteristic curve that can described relationship between the total valve location and the actual flow.

And the actual flow calculation is as shown in Eq.1

The actual flow $(\%)=\frac{G^{\prime}}{G}=\sqrt{\frac{p_{1}{ }^{2}-p_{2}{ }^{\prime 2}}{p_{1}{ }^{2}-p_{2}{ }^{2}}} \sqrt{\frac{t_{1}}{t_{1}{ }^{\prime}}}$

In Eq. $1, \mathrm{G}$ is the nominal flow, $\mathrm{G}^{\prime}$ is the flow under varying conditions, $\mathrm{P}_{1}$ is the nominal main steam pressure, $\mathrm{P}_{2}$ is adjusted stage pressure, $\mathrm{P}_{1}{ }^{\prime}$ is main steam pressure under varying conditions, $\mathrm{P}_{2}{ }^{\prime}$ is adjusted stage pressure under varying conditions, $t_{1}$ is the nominal main steam temperature, $t_{1}{ }^{\prime}$ is main steam temperature under varying conditions。 
According to the above identification method, two kinds of load oscillation proble caused by valve software problems and hardware problems is presented as shown in Fig.3. And the normal flow characteristic is also shown in Fig.3. Therefore, the advantage of this method to diagnose the fault is not necessary to carry out a special test but using the daily operation data.

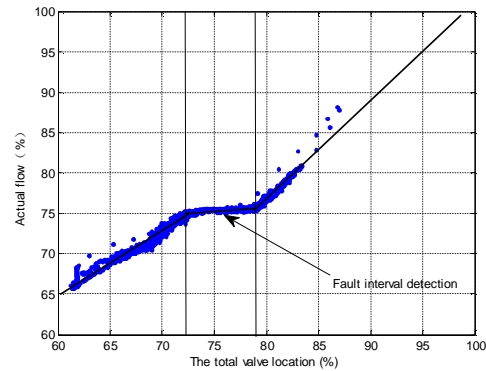

(a) Valve software problems

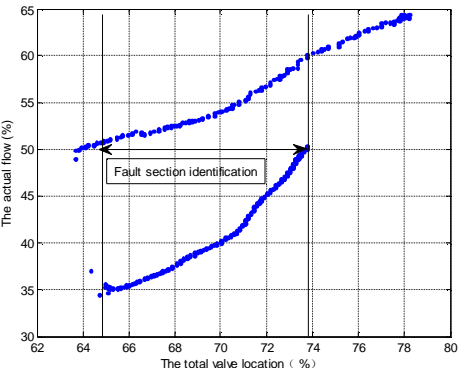

(b) Valve hardware problems

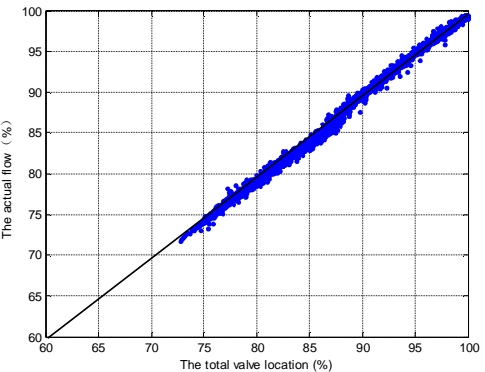

(c) Normal flow characteristic

Fig.3 Fault identification method for two kinds of load oscillation problem

\section{The Economic Solutions and Experimental Verification}

The load oscillation influences the units' regulation performance, especially to turbine's automatic generation controlling and primary frequency modulation. For software failures, we can use the valve management optimization techniques on the premise of non-stop to solve the high regulation valves' question that integrated flow characteristic curve linearity is poor as shown in Fig.4. For hardware failures, we can use valve management optimization and sliding pressure optimization to solve the question on the premise of non-stop. The specific way is to find one or more trouble-free valves through flow characteristic tests for the problem that the connection of valve hardware is loose. Then, the valves are used to find the steam distribution rules on a wide range of load regulation and the sliding pressure operation curve. Ultimately, optimization reconstruction results for the actual running units with HP-valve faults or malfunctions show that the new approach is effective. The optimized rule is designed by using GV4, without linkage fault. And the main steam pressure adjustment to regulate the unit load load variation is normal, which is shown in Fig.4.
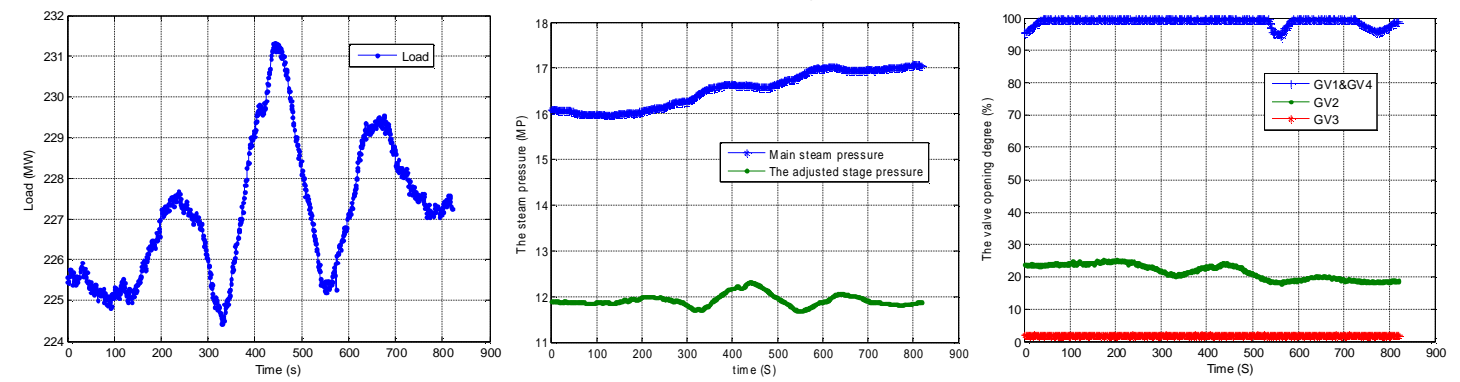

(a) The fault solving for a supercritical 350MW unit
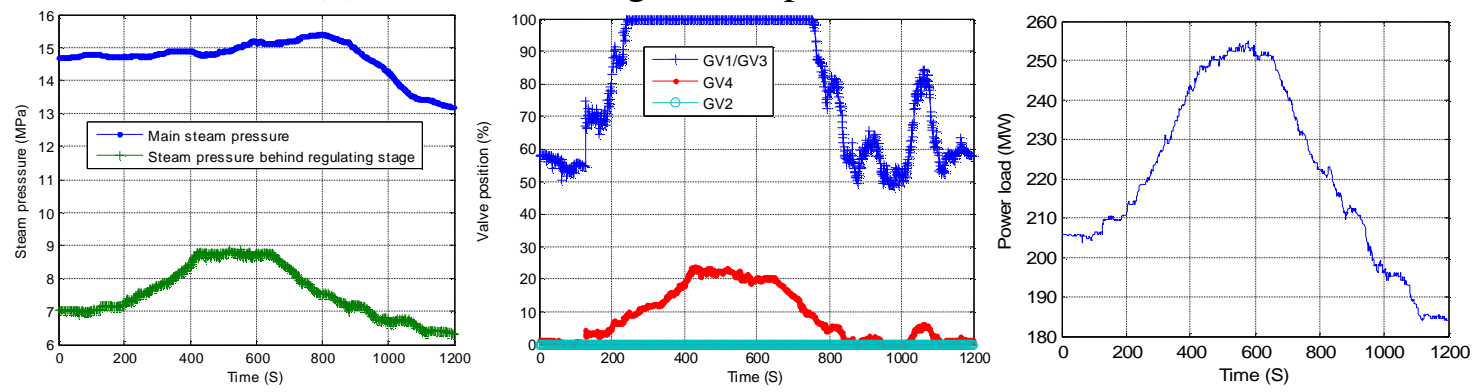

(b) The fault solving for a subcritical 330MW unit

Fig.4 Trouble shooting of the case unit 


\section{Conclusions and Prospects}

In this paper, two kind of turbine load oscillation fault is researched on based of studying two actual unit cases. And the obtained conclusions are as follows:

1) It's found that not only HP-valve's poor flow characteristics of software failure, but its loose connection parts of hardware failure can also cause unit load oscillation.

2) A method for fault identification with online monitoring are shown.

3) The common optimization for two kind HP-valves' fault is carried out with great engineering application value to guarantee units operation with safety and efficient.

In the future, the optimization design of the on-line monitoring software is also continued studying for a large number of actual case units to ensure the safety and efficiency of the thermal power unit in real time and large scale variable condition operation.

\section{Acknowledgement}

This work was sponsored by Harbin Program on Application Technology and Development Research of China under Grant 2012DB2CP022 and China Huaneng North United Power Power Co. Ltd itself financing technology projects under Grant HNBFKJ201505.

\section{References}

[1] Liu J, Bi T, Niu Y, et al, in: The utilization of large-scale renewable powers with high security and efficiency in smart grid, Power and Energy Society General Meeting, 2012 IEEE. IEEE, 2012:1-5.

[2] Q.H. Hu, P.Y. Su, D.R. Yu, et al: Sustainable Energy, IEEE Transactions on Vols. 3 (2014) p. 866 $-874$.

[3] J. Wan, Z.G. Zhao, G.R. Ren, et al: Advanced Materials Research Vols. 945-949 (2014) p. 2801-2805.

[4] D.R. Yu, Y.F. Duan, J.F. Liu, et al: ASME Journal of Engineering for Gas Turbines and Power Vol. 6 (2010), p. 1-4.

[5] J. Wan, J.S. Gu, G.R. Ren, etl: Applied Mechanics and Materials Vols. 536-537 (2014) p.1501-1509.

[6] Y. Cui, Z.S. Liu, D.R. Yu, et al: ASME Journal of Engineering for Gas Turbines and Power Vol. 7 (2012), p. 1-4.

[7] S. Adibhatla, S.C. Kaushik: Applied Thermal Engineering .73 (2014), pp: 49-63

[8] N. N. Trifonov, E. V. Kovalenko, V. I. Kurgin and S. B. Esin: Thermal Engineering, 2011, Vol. 58, No. 2, pp. 162-166.

[9] Liu J, Liu D, Wang B. in: Notice of Retraction The Thermal Economic Analysis for Turbine's Sliding Pressure Operation, International Conference on Information Science and Engineering. IEEE, 2009.

[10] F.P. Pan, W.P. Sun: Advanced Materials Research. 2013 (Volumes 634-638), pp:3757-3761.

[11] Gao L, Dai Y, Gao L, et al, in: Rotor dynamic analysis on partial admission control stage in a large power steam turbine, ASME Turbo Expo 2010: Power for Land, Sea, and Air, June. 2010:2219-2225.

[12] N. Sakai, T. Harada and Y. Imai: JSME International Journal, Series B, 2006, Vol.49, No.2, pp. 212-217. 